\title{
Voltammetric Insights in the Transfer of Ionizable Drugs Across Biomimetic Membranes - Recent Achievements
}

\author{
Rubin Gulaboski ${ }^{\mathrm{a}, \mathrm{b}, \mathrm{c}}$, Fernanda Borges ${ }^{*}, \mathrm{~d}$, Carlos M. Pereira ${ }^{*, a}$, M. Natália D.S. Cordeiro ${ }^{\mathrm{c}}$, \\ Jorge Garrido ${ }^{\mathrm{e}}$ and A. Fernando Silva ${ }^{\mathrm{a}}$
}

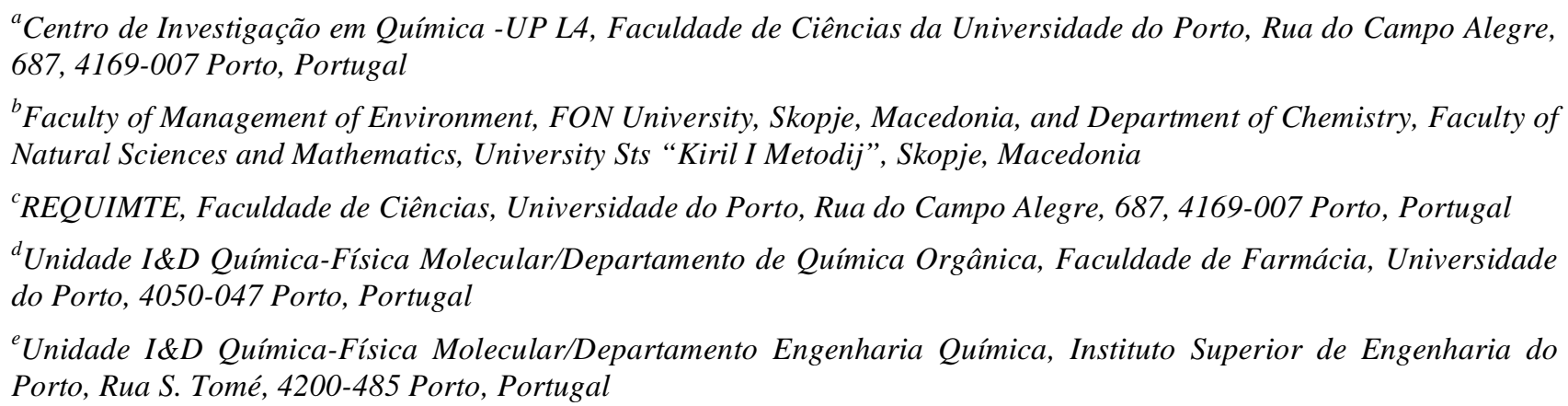

Abstract: The latest results of voltammetric research on the ionic transfer process of ionisable drugs across bare and lipid-modified liquid-liquid interfaces are reviewed. In recent years, two voltammetric methods have been extensively applied to this purpose, i.e. the classical four electrode voltammetry at the interface between two immiscible electrolyte solutions, and the "three-phase electrode." Thus, a brief background of the methodologies and some successful examples of their application are highlighted in this work. Particular attention is given to the ionic transfer kinetics and to the electrochemical characterization of the drug-membrane interactions between the ionized drugs and lipid-modified interfaces. Future trends in this area are also mentioned in connection with high-throughput assessment of ADMET properties of drugs.

Keywords: Partition coefficients, ionisable drugs, three-phase electrode, voltammetry, biomimetic membranes liquid-liquid interface.

\section{INTRODUCTION}

Partition coefficients of pharmaceuticals are of utmost importance during the early stage of the drug design process. In fact, the drug partition coefficient correlates with the drug lipophilicity and is used for the estimation of drug transformation events like absorption, metabolism, and also in modelling the distribution among compartments. Lipophilicity is one of the most important driving forces sustaining the passive transport of drugs through biomembranes, and it is a key factor in drug-receptor interactions [1-3].

Drug lipophilicity is considered to be one of the key physicochemical parameters that facilitates the prediction and understanding of the transport processes across biological barriers $[1,2]$. Drug biodistribution, protein binding and metabolism pathways are generally dynamic and interdependent processes that interplay and influence each other, both being strictly related to lipophilicity. Actually, the study of the ability of a drug to interact with membranes and enzymes is of extreme significance for a proper understanding of its biological or side effects.

\footnotetext{
*Address correspondence to these authors at the Unidade I\&D QuímicaFísica Molecular/Departamento de Química Orgânica, Faculdade de Farmácia, Universidade do Porto, 4050-047 Porto, Portugal; E-mail: fborges@ff.up.pt and Centro de Investigação em Química -UP L4, Faculdade de Ciências da Universidade do Porto, Rua do Campo Alegre, 687, 4169-007 Porto, Portugal; E-mail: cmpereir@fc.up.pt
}

After administration, a drug must cross cell membranes in order to reach the final target. Living-cell membrane is regarded as a natural barrier, which separates two phases having different physical properties and regulates, in a very strict way, the exchanging drug processes. Among the most important factors responsible for the mutual exchange of a drug across cell membranes is its intrinsic lipophilicity, commonly considered as its affinity towards a lipophilic environment. This property is usually measured as a drug|membrane partitioning process through its distribution in a biphasic system, such as water|oil systems [1-4]. Liquid systems comprising two immiscible solvents (one of which is generally water) forming a stable liquid-liquid interface have been shown to mimic the biological membranes [1-3]. The assessment of oil-water partition coefficients in general, and octanol-water partition coefficients in particular, have been widely used to describe the lipophilicity of neutral drugs, being in turn a molecular descriptor that is often used to establish quantitative structure-activity (QSAR), quantitative structure-toxicity (QSTR) and quantitative structuremetabolism (QSMR) relationships [1-5].

Actually, there is a requirement for the determination of drug partition coefficients either of the neutral or the ionic forms, since over $70 \%$ of the currently used drugs are ionisable under physiological conditions $[1,2]$. In fact, the importance of the lipophilicity of ionisable drugs and solutes has been underestimated mainly due to the lack of reliable 
methods to determine the partition coefficients of the ionic forms. However, the understanding of the lipophilicity of ionisable and ionic drugs has been limited by the lack of reliable experimental methods to estimate the partition coefficients. Recently, the introduction of voltammetric techniques has opened new perspectives for its evaluation and use in drug rational design and/or to understand their transfer process through the biological membranes.

The aim of this review is to highlight the recent advances in the electrochemical transfer of ionisable compounds. Since classical electrochemical methodology has several limitations, new systems with different phase ratios have been developed in order to extend the electrochemical measurements to attain important health data. In the present work, two systems - the "droplet system" using a small volume of organic phase [5], and four-electrode voltammetry [1-3] are considered as important techniques for the study of ionic transfer reactions. Attention is focused mainly on the papers published after 2002, since several reviews have been previously published on the topic [5-10].

\section{FOUR-ELECTRODE VOLTAMMETRY AT ITIES: A SHORT BACKGROUND}

Four-electrode voltammetry at the interface between two immiscible electrolyte solutions (ITIES) is frequently described as the first electrochemical technique suitable for the determination of the partition coefficients of ions [3]. This technique is referred as "classical" in ion transfer studies and comprises external (potentiostatic controlled) polarization of the interface between two immiscible electrolyte solutions. Each compartment contains one reference and one counter electrode similar to what is shown in Fig. 1A. When the applied potential difference between both conjoined liquid phases is equal to the standard potential of the ion transfer process of a given ion, then it will cross the liquid-liquid interface at an equal rate and, in the voltammetric output, will be portrayed in a single voltammogram. The voltammogram characteristics will depend on the nature of the transferred ion, on its charge and concentration, as well as on the temperature and the nature of the mass transfer phenomena $[1-3,11]$. The partition coefficient of an ion $\mathrm{i}\left(\log P_{\mathrm{i}}\right)$ is assumed to be a direct measure of its lipophilicity. It is linked to the Galvani potential difference across the interface, as shown by the following equations (1 to 3 ):

$$
\begin{aligned}
& \log \left(P_{i}\right)=-\frac{\Delta G_{\mathrm{i} w}^{\ominus 0}}{2.3 \mathrm{RT}}+\frac{z_{\mathrm{i}} F}{2.3 R T} \Delta \varphi_{\mathrm{w}}^{\mathrm{o}} \\
& \log \left(P_{i}\right)=\log \left(P_{\mathrm{i}}^{\ominus \mathrm{o}}\right)+\frac{z_{\mathrm{i}} F}{2.3 R T} \Delta \varphi_{\mathrm{w}}^{\mathrm{o}} \\
& \log \left(P_{\mathrm{i} \text { w }}^{\ominus \mathrm{o}}\right)=-\frac{\Delta G_{\mathrm{i} \mathrm{w}}^{\ominus \mathrm{o}}}{2.3 \mathrm{RT}}
\end{aligned}
$$

where $\log \left(P_{\mathrm{i}}^{\ominus 0}\right)$ is the standard partition coefficient of the ionic solute i transferred from the water $(w)$ into the organic (o) phase. In the above equations, $\Delta \varphi_{\mathrm{w}}^{\mathrm{o}}$ is the Galvani potential difference between the water and the organic phase,
A

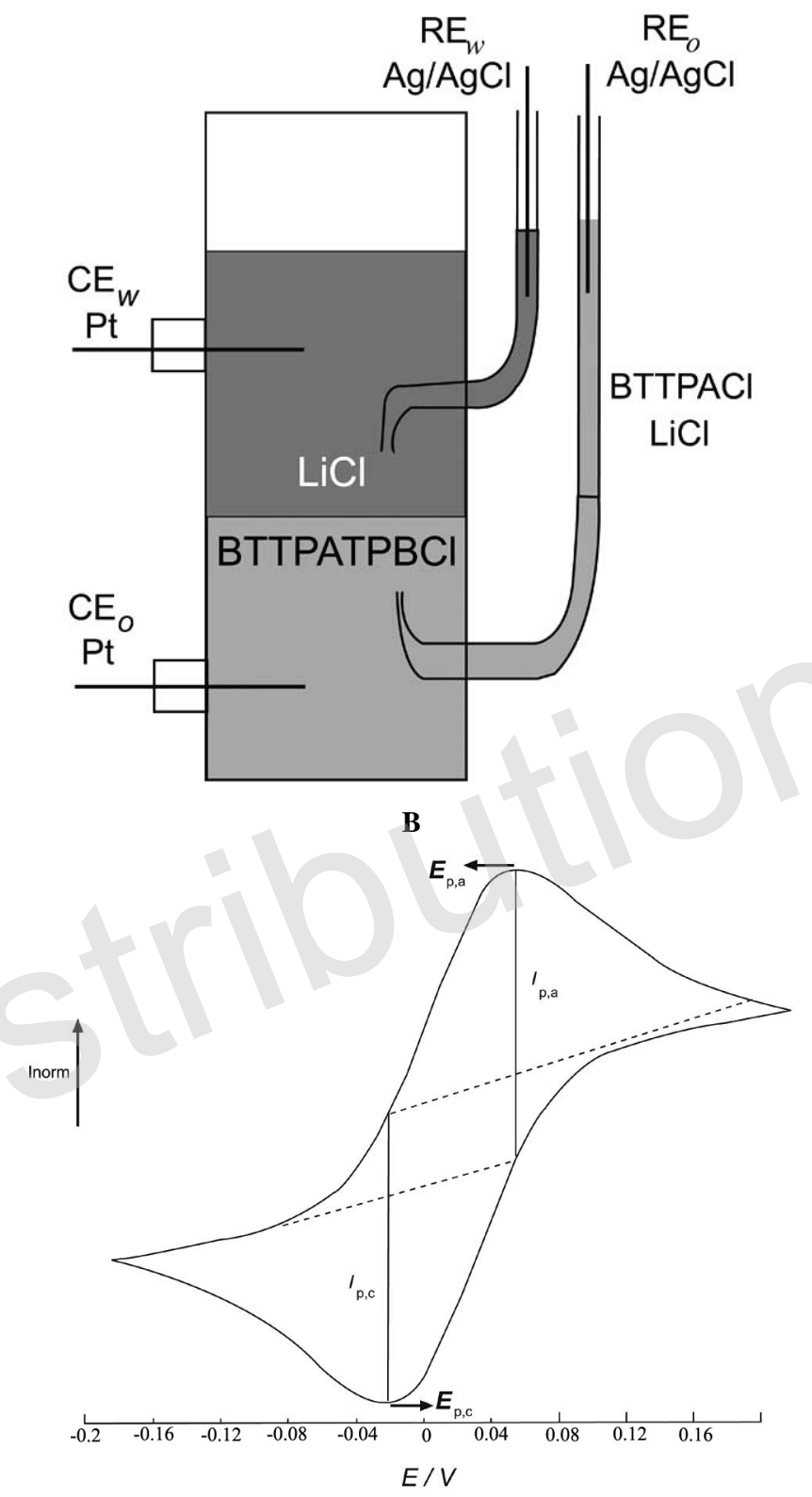

Fig. (1). A) Diagram of a four electrode cell for electrochemical studies at the liquid|liquid interface. The aqueous electrolyte (top solution) contains $\mathrm{LiCl}$ as supporting electrolyte, while the organic phase contains a highly lipophilic organic electrolyte. The cation is bis(triphenylphosphoranylidene) ammonium $\left(\mathrm{BTPPA}^{+}\right)$and the anion tetrakis(4-chlorophenyl)borate $\left(\mathrm{TPBCl}^{-}\right)$. Pt-wires $(\mathrm{CE})$ and $\mathrm{Ag} / \mathrm{AgCl}(\mathrm{RE})$ operate as counter and reference electrodes in water and organic phases. B) Cyclic voltammogram showing the ion transfer of an anion compound across a liquid-liquid interface. $E_{\mathrm{p} \text {,a }}$ is the anodic peak potential, $E_{\mathrm{p}, \mathrm{c}}$ is the cathodic peak potential, while $I_{\mathrm{p}, \mathrm{a}}$, and $I_{\mathrm{p}, \mathrm{c}}$, are the anodic and cathodic peak currents, respectively. The mid-peak (or half-peak) potential $\Delta E_{\mathrm{p} / 2}$ is the median potential between $E_{\mathrm{p}, \mathrm{a}}$ and $E_{\mathrm{p}, \mathrm{c}}\left[\right.$ i.e. $\left.\Delta E_{\mathrm{p} / 2=}\left(E_{\mathrm{p}, \mathrm{a}}+E_{\mathrm{p}, \mathrm{c}}\right) / 2\right]$.

while $\Delta G_{\mathrm{i} \mathrm{w}}^{\ominus 0}$ is the standard Gibbs energy of transfer of the ionic solute $\mathrm{i}$ from the water to the organic phase. $\Delta G_{\mathrm{i} \text { w }}^{\ominus 0}$ (and consequently $\log \left(P_{\mathrm{i}}^{\ominus \mathrm{w}}\right)$ ) is related to the standard potential of ion $\operatorname{transfer}\left(\Delta \varphi_{\mathrm{i} w}^{\ominus 0}\right)$, i.e. 
$\Delta \varphi_{\mathrm{i} w}^{\ominus \mathrm{o}}=-\frac{\Delta G_{\mathrm{i} \mathrm{w}}^{\ominus \mathrm{o}}}{z_{\mathrm{i}} F}$

This latter parameter is linked to the voltammetric midpeak potential of the ion transfer $\Delta \varphi_{i}^{1 / 20}$, which is deducible from the experimental voltammetric outputs (i.e. it is the median between the cathodic and anodic peaks at Fig. 1B). It is worth noticing that cyclic [3] and square-wave voltammetry $[5,8,12]$ at the ITIES are appropriate techniques for the determination of the standard partition coefficients of ionic solutes $\left(\log \left(P_{\mathrm{i}}^{\ominus \mathrm{o}}\right)\right.$ due to the external control use of the interfacial potential, and therefore of the ionic distribution between the two adjacent phases. Moreover, for a biphasic system, the partition coefficient of an ion "i" is defined as: $P_{\mathrm{i}}=$ $c(\mathrm{i})_{\mathrm{o}} / c(\mathrm{i})_{\mathrm{w}}$. The partition coefficients values of different categories of compounds determined by this technique are depicted in Tables 1,2. A positive $\log \left(P_{\mathrm{i}}^{\ominus \mathrm{w}}\right)$ value is directly correlated with a high lipophilicity performance of the ionisable compound "i" under study.

\section{"THREE-PHASE" ELECTRODE VOLTAMMETRY (DROPLET SYSTEM): A SHORT BACKGROUND}

The droplet system is based on the simple deposition of an organic drop containing a redox probe onto the surface of a graphite electrode which is immersed into an aqueous electrolyte solution. This process, also called a "three-phase electrode", was developed by Scholz and Lovrić's [13] and offers a unique way for determining the standard Gibbs energy of ion transfer across a liquid|liquid interface [6-8]. So, as this droplet system ensures a rapid equilibrium between the phases, it has been largely applied to the study of ion transfer processes that were difficult to attain with classical techniques $[3,5,9,11]$. Actually, the system voltammetric response depends on the redox reactions that occur on the solid electrode and the charge transfer reactions at the interface between two immiscible electrolyte solutions (ITIES). These reactions can be either ion transfer (IT) or ion and electron transfer (IT/ET) processes. In this technique, a small amount of a neutral electroactive compound (i.e. a redox probe) is dissolved in an organic and water immiscible solvent. A droplet ( $1 \mu \mathrm{L}$ or smaller) of the solution is then placed on the surface of the working electrode. This procedure works better with graphite electrodes (e.g., PIGE) than metal electrodes. The droplet-modified working electrode is then immersed in an aqueous s $\left(\mathrm{Cat}^{+} \mathrm{X}^{-}\right)$electrolyte solution. The reference and counter electrodes are placed in the water solution as in a conventional voltammetric cell (Fig. 2A). A technique prerequisite is the existence of a three-phase junction line where the working electrodes, the organic and aqueous solutions link to each other. If the neutral redox probe, dissolved in the organic solvent, can undergo oxidation under anodic polarization of the potential, then an excess of positive ions will be produced into the organic phase. The electron transfer process occurring at the electrode|organic phase interface must be coupled with an ion transfer process across the aqueous phase|organic phase interface. In that way, the electroneutrality of the organic phase
Table 1. Partition Coefficients of the Protonated Forms (Taken from Reference [15]) of Di- and Tripeptides Determined by Four-Electrode Voltammetry at ITIES at a Water and Nitrobenzene (NB) Interface

\begin{tabular}{|c|c|}
\hline Compounds & $\log P_{\mathrm{HA}^{+}}^{\theta}{ }^{\mathrm{w} \rightarrow \mathrm{NB}}$ \\
\hline Gly-Phe & -3.20 \\
\hline Ile-Phe & -1.95 \\
\hline Ile-Ile & -2.52 \\
\hline Ile-Leu & -2.45 \\
\hline Trp-Gly & -3.04 \\
\hline Leu-Leu & -2.00 \\
\hline Phe-Leu & -1.42 \\
\hline Phe-Phe & -0.91 \\
\hline Phe-Leu-Leu & -1.74 \\
\hline Trp-Leu-Leu & -1.11 \\
\hline Leu-Leu-Ala & -3.30 \\
\hline Leu-Leu-Val & -2.55 \\
\hline Leu-Leu-Leu & -2.18 \\
\hline Val-Val-Val & -3.64 \\
\hline Phe-Phe-Phe & -0.55 \\
\hline Val-Phe-Phe & -1.67 \\
\hline Ala-Phe-Phe & -2.21 \\
\hline Phe-Phe-Ala & -2.54 \\
\hline Phe-Phe-Val & -1.57 \\
\hline Phe-Val-Val & -2.57 \\
\hline Val-Val-Phe & -2.76 \\
\hline Leu-Val-Phe & -2.32 \\
\hline Phe-Val-Phe & -1.69 \\
\hline Phe-Val-Leu & -2.11 \\
\hline Trp-Val-Phe & -1.27 \\
\hline Trp-Val-Leu & -1.54 \\
\hline Leu-Trp-Val & -1.86 \\
\hline Val-Trp-Leu & -1.72 \\
\hline Phe-Trp-Val & -1.30 \\
\hline Val-Trp-Phe & -1.42 \\
\hline Leu-Phe-Phe & -1.18 \\
\hline Phe-Phe-Leu & -1.08 \\
\hline
\end{tabular}

is maintained. In the voltammetric experiments, both the electron and ion transfer processes are portrayed in a single voltammogram. The type of ion transfer process that takes place, i.e., the transfer of anions from water to the organic phase or the transfer of electrochemical generated cations from the organic phase to water, depends primarily on the 
Table 2. Partition Coefficients (Taken from Reference [27]) of the Protonated Forms of Drugs of Abuse and Their Metabolites Determined by Four-Electrode Voltammetry at ITIES with a Water and 1,2Dichlorethane (DCE) Interface

\begin{tabular}{|c|c|}
\hline Compounds & $\log P_{\text {DrugH }^{\theta}}{ }^{\mathrm{w} \rightarrow \mathrm{DCE}}$ \\
\hline \hline Heroin & -0.58 \\
\hline 6-Monoacetylmorphine (6-MAM) & -2.45 \\
\hline Morphine & -4.55 \\
\hline Acetylcodeine & -1.55 \\
\hline Codeine & -2.00 \\
\hline Dihydrocodeine & -3.95 \\
\hline Methamphetamine & -2.03 \\
\hline Amphetamine & -2.52 \\
\hline Ecstasy (MDMA) & -3.22 \\
\hline 3,4-Methylenedioxy amphetamine (MDA) & -3.55 \\
\hline 3-Methoxy- $\alpha$-methyldopamine (3-OMe- $\alpha$-MeDA) & -1.83 \\
\hline$\alpha$-Methyldopamine $(\alpha$-MeDA) & -3.82 \\
\hline
\end{tabular}

ratio of the standard Gibbs energies of ions transfer. In general, if the solvation of the electrochemically produced cations $\mathrm{Ox}^{+}$in the organic phase is stronger than the anions hydration in the aqueous phase $\mathrm{X}^{-}$, then its transference from the aqueous phase towards the organic phase will occur (Fig. 2B). A cation transfer process from the aqueous phase towards the organic phase can be induced if the solvation of electrochemically generated anions in the organic phase, generated by the reduction of a neutral electro reducible compound present in the organic phase, is stronger than the hydration of the cations in the aqueous phase. In both cases, the standard Gibbs energies of ion transfer can be deduced from the formal potentials of cyclic or square-wave voltammograms.

According to the scheme represented in Fig. 2B, the overall reaction proceeding at a micro-droplet modified electrode can be written as follows:

$\operatorname{Red}_{(\mathrm{o})}+\mathrm{A}_{(\mathrm{aq})}^{-} \leftrightarrows \mathrm{Ox}_{(\mathrm{o})}^{+}+\mathrm{A}_{(\mathrm{o})}^{-}+\mathrm{e}^{-}$

If there are no kinetic constrains with respect to the electron and ion transfer, the reaction thermodynamic treatment (I) leads to the following form of the Nernst equation:

$E_{\mathrm{C}}^{\Theta^{\prime}}=E_{\mathrm{Ox}_{(\mathrm{o})}^{+} / \operatorname{Red}(\mathrm{o})}^{\Theta}+\Delta \phi_{\mathrm{aq}}^{\mathrm{O}}, \stackrel{\ominus}{\mathrm{A}^{-}}-\frac{R T}{F} \ln c\left(A^{-}\right)_{a q}+\frac{R T}{F} \ln \frac{c^{*}(\operatorname{Re} d)_{0}}{2}$

In equation (5) $\left(E_{\mathbf{C}}^{\Theta^{\prime}}\right)$ is the formal (half-wave) potential of the system, $E_{\mathrm{Ox}_{(\mathrm{o})}^{+} / \operatorname{Red}(\mathrm{o})}^{\theta}$ is the standard potential of the redox couple $\mathrm{Ox}^{+} /$Red in the organic solvent, $\Delta \phi_{\mathrm{aq}}^{\mathrm{O}},{ }_{\mathrm{A}^{-}}$is the standard potential of transfer of anions from the aqueous phase to the organic phase, $c\left(\mathrm{~A}^{-}\right)_{\text {aq }}$ is the initial concentration of the anions in the water phasewhile $c^{*}(\operatorname{Red})_{\mathrm{o}}$ is the initial concentration of the redox probe in the organic solvent. $R, F$, and $T$ are gas and Faraday constants and thermodynamic temperature, respectively. The equation also shows that the formal potential of the voltammograms that represent coupled electron and ion transfer processes at a three-phase electrode depends on the nature of the anions in aqueous phase (via the values of $\Delta \phi_{\mathrm{aq}}^{\mathrm{o}}, \frac{\theta}{\mathrm{A}^{-}}$). Generally, the more lipophilic anions give the more negative $\Delta \phi_{\mathrm{aq}}^{\mathrm{o}}, \stackrel{\ominus}{\mathrm{A}^{-}}$values. Consequently, the oxidation of the compound (Red) in the organic phase will occur at more negative potentials (i.e. it will be easier oxidized), a value that increases with the lipophilicity (Fig. 2C). Moreover, for the individual anions present in the aqueous phase, the formal potential will shift by $\sim 59 \mathrm{mV}$ in negative direction for a 10 -fold increase of the concentration of the transferable anions in the aqueous phase. The reversibility of the processes can be deduced by taking together the previous criterion and the stability of the voltammograms recorded during manifold cycling.

On the other hand, the reduction of an electro reducible compound $(\mathrm{Ox})$ dissolved in the organic phase can induce cation transference from the water towards the organic phase. This process can be described by the following reaction:

$\mathrm{Ox}_{(\mathrm{o})}+\mathrm{Cat}_{(\mathrm{aq})}^{+}+\mathrm{e}^{-} \leftrightarrows \operatorname{Red}_{(\mathrm{o})}^{-}+\mathrm{Cat}_{(\mathrm{o})}^{+}$

In the same way, the thermodynamic treatment of reaction II leads to the following Nernst equation (applicable if the cations are transferred from the aqueous toward the organic phase):

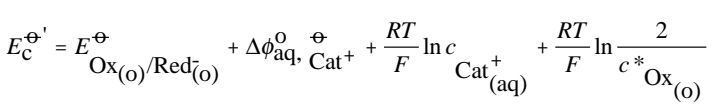

Thus, more lipophilic cations present more positive $\Delta \phi_{\mathrm{aq}}^{\mathrm{o}}, \stackrel{\ominus}{\mathrm{Cat}^{+}}{ }^{+}$values. Subsequently, the organic compound reduction (Ox) in the oil phase will occur at more positive potentials as the lipophilicity of the cations in the aqueous phase increases. The formal potential of the coupled electron/ion reaction at the three-phase electrode will shift 59 $\mathrm{mV}$ in the positive direction for a 10 -fold increase of the concentration of the transferable cations in the aqueous solution.

In opposition to the four-electrode voltammetry, this technique operates with rather small organic-to-water phase volume ratios and can work with the common threeelectrode potentiostats $[6-8,10]$. Actually, this technique has been recently introduced to overcome some of the limitations of the four electrode voltammetry at ITIES, which are mainly related to restrictions on the type of organic solvents.

\section{PARTITION COEFFICIENTS OF IONIC DRUGS DE- TERMINED BY FOUR ELECTRODE VOLTAMME- TRY AT ITIES}

The study of lipophilicity and transport properties of ionisable drugs is a current subject of research $[1,2,6]$. 
A)

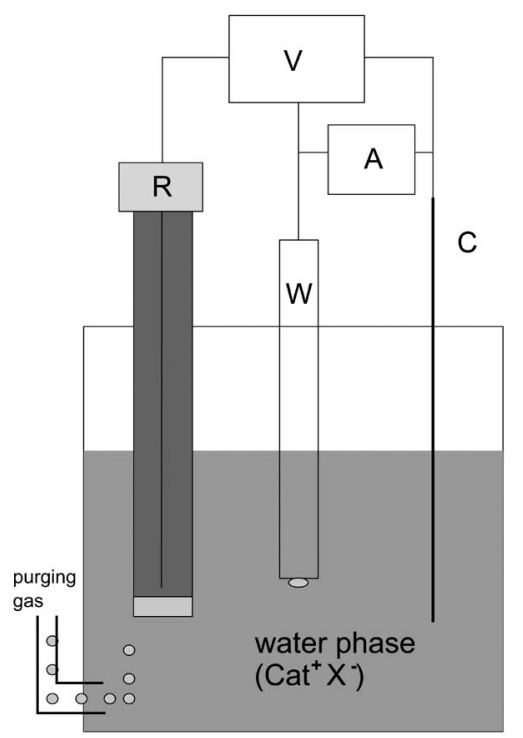

B)

C)
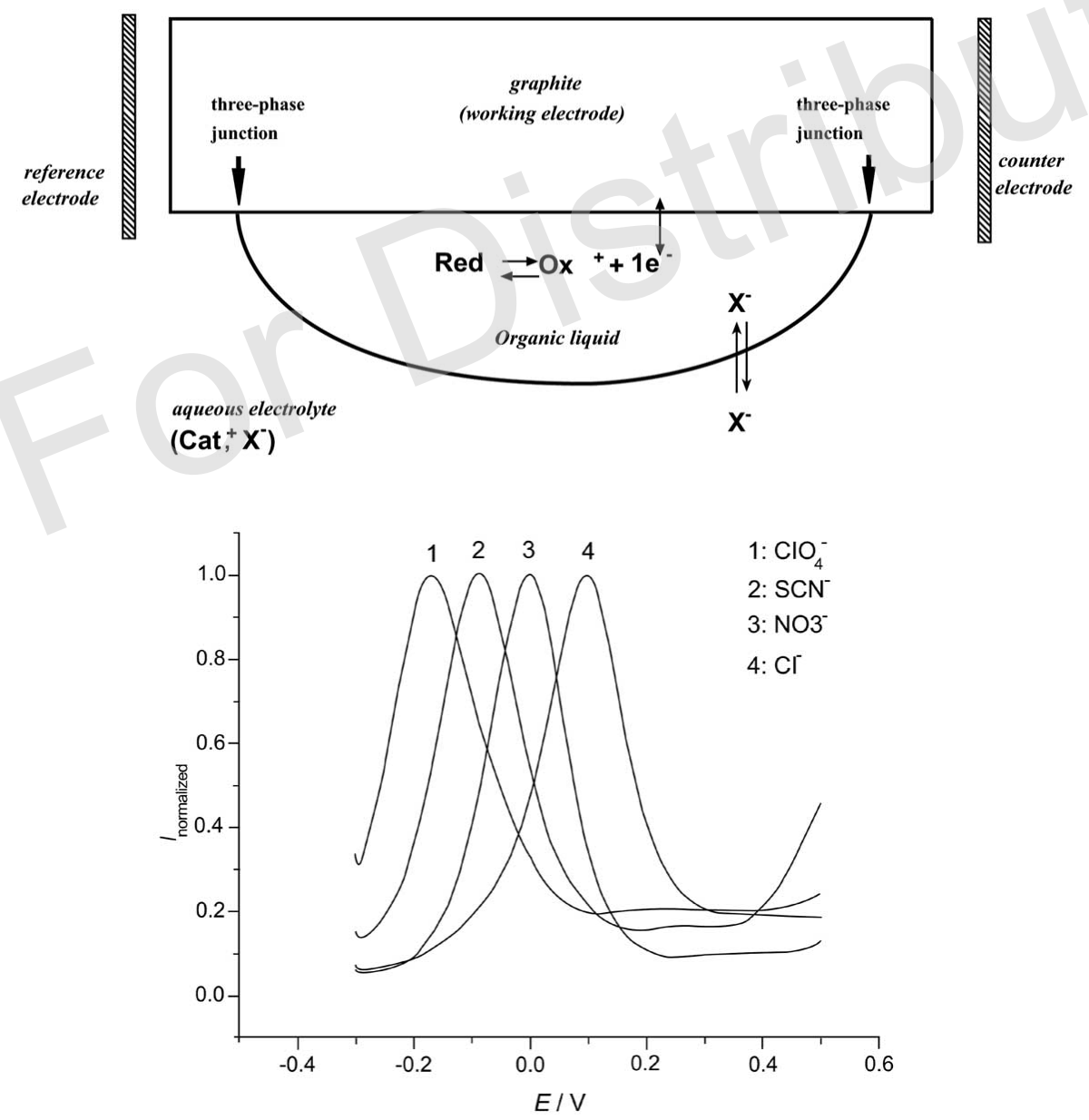

Fig. (2). A) Voltammetric cell used in a "three-phase electrode" system. R=reference electrode; C=counter electrode; W=working electrode; $\mathrm{V}=$ voltmeter; $\mathrm{A}=$ ampere meter. The working electrode is a small droplet of an organic solvent containing an electroactive redox probe. B) Schematic representation of the process taking place at the "three-phase electrode", when the lipophilic oxidizable compound (Red) is dissolved in the organic solvent. $\mathrm{Cat}^{+}$and $\mathrm{X}^{-}$are the symbols for cations and anions, respectively, present in the aqueous phase. C) Square-wave voltammograms representing different anionic transfer processes across a water-nitrobenzene interface. Decamethylferrocene was the redox probe in the organic phase. 
Thus, the determination of the lipophilicity of ionic amino acids and peptides is a very important mission in the health sciences, mainly due to their relevant biological activities related, for instance, to folding processes. In addition, knowledge of this property has been found to be important for applications such as binding affinity prediction of a membrane protein to a lipid bilayer $[1,2]$.

Since peptides are currently used as therapeutic drugs, this type of information is highly valuable either for ADMET studies or for attaining quantitative-structure activity relationships (QSAR) [1, 2]. The assisted transfer of protonated amino acids at the water-1,2-dichloroethane interface was systematically studied by Chen et al. [14]. However, this study only resulted in the acquisition of data for 10 protonated natural amino acids [i.e. tryptophan (Trp), phenylalanine (Phe), leucine (Leu), valine (Val), isoleucine (Ile), methionine (Met), alanine (Ala), glycine (Gly), cysteine (Cys), and glutamine (Gln)], mainly due to technical limitations. The partition coefficients of these amino acids have been positively correlated with their complexation constants using a crown ether as a facilitator. A comprehensive study concerning the evaluation of di- (18) and tri-(27) peptides lipophilicity properties, at the water-nitrobenzene interface, has been performed by Osakai et al. [15]; the corresponding partition coefficients values of protonated di- and tripeptides are shown in Table 1. A quantitative property-structure relationship study, through a non-assisted and facilitated transfer process, of the protonated forms of the amino acids (or peptides) was undertaken. It was concluded that the hydrophilicity of the protonated peptides is governed not only by the intrinsic lipophilicity of the peptide backbone, as previously thought, but also by the steric effects of the bulky side chains [15].

A voltammetric study at a polarized interface between two immiscible electrolyte solutions of important biologic polypeptides has been reported for the highly charged polypeptide protamine [16]. Chronoamperometry using a micropipette has also been successfully used for charge transference and diffusion coefficient determination of this type of polypeptide protamine [17]. Kontturi et al. [18] evaluated the partition coefficient values from cyclic voltammetric measurements at a polarized water-NPOE interface of drugs used in therapy, like those structurally related to aminoacridines: aminacrine $\left(\log P_{\mathrm{w}}^{\mathrm{NPOE}}=-1.63\right)$, proflavine $\left(\log P_{\mathrm{w}}^{\mathrm{NPOE}}=-1.65\right)$, tacrine $\left(\log P_{\mathrm{w}}^{\mathrm{NPOE}}=-1.97\right)$, and velnacrine $\left(\log P_{\mathrm{w}}^{\mathrm{NPOE}}=-0.24\right)$. The results obtained on the study of drug membrane activity, by combining a theoretical model to electrochemical impedance spectroscopy experiments, permitted the justification of some of the differences found between their therapeutic activities [18]. A facilitated (assisted) ion transfer study of the protonated neurotransmitter dopamine (often used in neuropsychosis treatment) using dibenzo-18-crown- 6 crown ether was reported by Zhan et al. [19] and Beni et al. [20]. Ascorbate, which is a recycling redox agent that interacts with dopamine activity, was shown to be non-transferable with this facilitator. Tsukamoto et al. [21] developed an interesting study on the transfer process at various $\mathrm{pH}$ values of the salt forms of several histamine and antihistaminic drugs (chlorpheniramine, clemastine, diphenhydramine, cyproheptadine, meclizine, promethazine, ketotifen, and terfenadine). The authors studied the transfer of the protonated forms of these drugs in solutions at various $\mathrm{pH}$ values. The $\log P$ values were reported to be more reliable than those obtained by conventional shake-flash techniques. The partition coefficients of other important therapeutic drugs - amitriptyline (antidepressant) and trihexyphenidyl (antiParkinson agent) - were also studied at the polarized water-1,2 dichloroethane interface [22]. Ion transfer studies of local anaesthetics at the water-nitrobenzene interface have been performed: procaine $(\log P=1.1)$, tetracaine $(\log P=$ $2.7)$, oxybuprocaine $(\log P=3.1)$, prilocaine $(\log P=0.0)$, mepivacaine $(\log P=0.8)$, lidovacaine $(\log P=0.9)$, bupivacaine $(\log P=2.0)$, and dubucaine $(\log P=2.8)$ [23]. The obtained parameters might be helpful in understanding their mode of action as well as for QSAR studies. A study of the ion transfer of several tetracycline antibiotics (tetracycline, oxitetracycline and 7-chlortetracycline), across a waterdichloroethane interface has been recently reported by Fernandez and Dassie [24]. The stabilities of these antibiotics and the partition coefficients of the protonated forms of these antibiotics and several of their degradation products have been studied in highly basic and acidic media [24].

The transfer process of the salt forms of $\beta$-blockers, i.e. propranolol $\left(\log P_{\mathrm{w}}^{\mathrm{DCE}}=2.3\right)$, sotalol $\left(\log P_{\mathrm{w}}^{\mathrm{DCE}}=5.6\right)$ and timolol ( $\log P_{\mathrm{w}}^{\mathrm{DCE}}=3.5$ ), was studied by cyclic voltammetry at an agarose modified water-1,2-dichloroethane interface [25]. The agarose gel can only influence the drugs diffusion coefficients. Phenothiazine salt derivatives are antipsychotic agents, regarded as potent modulators of multidrug resistance, that were also studied using cyclic voltammetry across the water-1,2-dichloroethane interface [26]. Their partition coefficients were calculated from the transfer potentials measured at $\mathrm{pH}<\mathrm{pK}_{\mathrm{a}}$ values ((promazine $\log P_{\mathrm{w}}^{\mathrm{DCE}}=-1.23$, chlorpromazine $\log P_{\mathrm{w}}^{\mathrm{DCE}}=-0.85$, trifluopromazine $\log P_{\mathrm{w}}^{\mathrm{DCE}}-$ 0.54 , methotrimeprazine $\log P_{\mathrm{w}}^{\mathrm{DCE}}=-1.05$, perphenazine $\log P_{\mathrm{w}}^{\mathrm{DCE}}=0.20$ and fluphenazine $\log P_{\mathrm{w}}^{\mathrm{DCE}}=0.76$ ). In order to establish relationships, the substituent effects and activities were correlated with Hammett substituent constants.

The partition coefficients (Table 2) of the cationic forms of several opioids, amphetamine-like drugs and their metabolites - heroin, 6-monoacetylmorphine (6-MAM), morphine, acetylcodeine, codeine, dihydrocodeine, methamphetamine, amphetamine, 3,4-methylenedioxymethamphetamine (MDMA or "ecstasy"), 3,4-methylenedioxyamphetamine (MDA), 3-methoxy- $\alpha$-methyldopamine (3-OMe- $\alpha$ MeDA), and $\alpha$-methyldopamine $(\alpha-\mathrm{MeDA})$ - were determined using electrochemical measurements at a polarized water-1,2-dichloroethane interface between two immiscible electrolyte solutions (ITIES) [27]. The drug partition coefficient values were correlated to the chemical structure and with the metabolic pathways central to each type of drug. Although the mechanisms that underlie the toxicity of this type of drugs are still unclear, the data indicated that the metabolite lipophilicity may be a contributing factor to their 
toxicity. A systematic facilitated ion-transfer voltammetric study of the anticoagulant heparin can be found in a recent work published by Guo et al. [28]. In this study, several quaternary ammonium salts were used as facilitators for heparin transfer across blood-plasma and a 1,2-dichloroethane interface. The anionic heparin transfer response was shown to strongly depend on the nature of the cation present in the membrane phase, which probably acts as a heparin-carrier (facilitator). Polyvinyl chloride plasticized 1,6-dichlorohexane membrane, placed between two aqueous electrolyte solutions, has also been used to follow the heparin ion transfer [29]. This method was foreseen to have potential clinical applications in plasma heparin determination.

Girault et al. [30] developed a new electrochemical method for lipophilicity determination based on a liquid layer immobilized between two aqueous compartments. The method was found to be a successful tool for drug partition coefficient determinations across several water-organic phase interfaces, for example, for the monobase tetramethylaniline and the monoacid dinitrophenol. The optimization of the method for high-throughput applications was accomplished using 96-well microfilter plates. Later, a new experimental set-up for ion transfer studies across the waterorganic oil microhole-interface was developed for the determination of the partition coefficients of tetramethylaniline and dinitrophenol [31]. This method is based on a twoelectrode microinterface set-up, where a commercial immobilized $\mathrm{pH}$ gradient gel is taken as the aqueous phase, and can be seen as a valuable alternative to study the ion transfer and construction partition diagrams of ionisable compounds. Recently, an alternative voltammetric method using media with low ionic strength has emerged for the study of ion transfer at micro- and nano-interfaces [32].

\section{PARTITION COEFFICIENTS OF IONIC DRUGS DE- TERMINED BY THE “THREE-PHASE" ELECTRODE}

The development of the droplet-modified (three-phase electrode) systems has led to significant progress in the lipophilicity determination of ionisable compounds (e.g., ionic aminoacids). It should be noted that these types of values could not be determined using the classical four-electrode technique at ITIES due mainly to its narrow potential window [5, 7-11]. By using the voltammetry at three-phase electrodes, Mirceski et al. [33] and Gulaboski et al. [34] recently reported the partition coefficients of the ionic forms of amino acids at the interface between water and nitrobenzene. In addition, the technique has been applied for the partition coefficients determination of several monoanionic forms of di-, tri- and polypeptides using decamethylferrocene as a redox probe and a water-nitrobenzene interface (Table $\mathbf{3}$ ) [35]. Interesting comments about the lack of reliable lipophilicity determinations in QSAR analysis and predictions of drug-membrane interactions have been pointed out by Bouchard et al. [36] who reported the lipophilicity of 26 ionisable drugs, some of them of therapeutic application, using the droplet-modified electrode at the water- $n$-octanol interface. Although $n$-octanol has been considered of extreme importance as a biomimetic membrane agent, it is known to be an ineffective solvent in the classical voltamme- try at ITIES due to its non-polarizability (i.e. no suitable electrolyte can be dissolved) [1-3]. This limitation has been overcome with the development of the three-phase electrode system since no electrolyte in the organic phase is needed to perform measurements $[7,8,13]$. Accordingly, the partition coefficients of 26 anionic drugs and pharmaceuticals was undertaken at water-nitrophenyloctyl ether and waternitrobenzene interfaces (Table 4) [36, 37]. The last study may be considered important in that it compared the solvation properties of the employed organic solvents.

The three-phase electrode set-up has been applied to chiral recognition through the study of the ion transfer of anionic chiral amino acids at the water and chiral organic solvents interface [38, 39]. This strategy has been also proposed as a potential analytical tool for chiral-drug separations [36, 37].

Compton et al. [40-43] obtained significant data for biologically active compounds by exploring the redox and lipophilic properties of vitamin K1 [40], $p$-chloranil [41], and vitamin B-12 [42] with immobilized electroactive organic droplets. Inverse experiments for the evaluation of lipophilic parameters in water droplets immobilized on organic electrodes subsequently submersed into organic electrolyte solutions have also been used [43]. Other recent and important contributions in the field of ionic drug transfer studies, obtained by using the three-phase electrode, were reported by Opalo and Marken et al. [44-48], Karyakin et al. [49-51], Pereira et al. [52], and Mirceski et al. [53, 54]. Detailed information on the application and fundaments of the threephase electrode process can be find in reviews by Scholz et $a l$. [7, 8] and Marken [6] reviews.

\section{TRANSFER OF DRUGS ACROSS LIPID-MODIFIED BIOMIMETIC MEMBRANES}

The absorption and uptake of drugs is a process essentially dependent on the composition of the cell membrane. Actually, drug-membrane interactions are known to influence drug transport and accumulation. As these events are directly related to drug efficacy, it is believed that its prediction could be used in the design of new and more selective therapeutics.

The drug partition studies between the membrane and aqueous compartments are generally performed through thermodynamic models, such as the $n$-octanol-water partitioning system $[1,2]$. The organic solvent is usually chosen due to its structural resemblance to the lecithins, which are biological membrane constituents [1]. Since the $n$-octanolwater interface is non-polarizable, its use is limited to certain electrochemical techniques [1,2]. Alternative approaches like lipid-modified and liquid-liquid interfaces of several polarizable organic solvents have been explored as good mimic systems of the biological membranes [1,55]. Lipid bilayer membranes are interphase systems containing ordered gradients inside the membranes. In many cases, the bulk systems lead to the determination of partition coefficients comparable to those obtained in biological partitioning 
Table 3. Anion Transfer Standard Potential $\left(\Delta \phi_{\mathrm{A}^{-}}^{\Theta^{\mathrm{W} \rightarrow \mathrm{NB}}}\right)$, Anion Transfer Standard Gibbs Energy $\left(\Delta G_{\mathrm{A}^{-}}^{\theta_{\mathrm{W}} \rightarrow \mathrm{NB}}\right)$ and Standard Partition Coefficient ( $\log P_{\mathrm{A}^{-}}^{\boldsymbol{\theta}_{\mathrm{w} \rightarrow \mathrm{NB}}}$ ) of Anionic Forms of Amino Acids and Peptides (Taken from Reference [35]) Determined by Three-Phase Electrode Voltammetry at a Water-Nitrobenzene Interface (Decamethylferrocene was Used as a Redox Probe)

\begin{tabular}{|c|c|c|c|}
\hline Gly $^{-}$ & 0.275 & 26.60 & -4.65 \\
\hline $\mathrm{Ala}^{-}$ & 0.285 & 27.50 & -4.80 \\
\hline $\mathrm{Leu}^{-}$ & 0.245 & 23.90 & -4.20 \\
\hline $\mathrm{Phe}^{-}$ & 0.215 & 21.00 & -3.70 \\
\hline Tyr & 0.220 & 21.20 & -3.72 \\
\hline Met $^{-}$ & 0.255 & 24.50 & -4.30 \\
\hline Pro & 0.305 & 29.50 & -5.20 \\
\hline His $^{-}$ & 0.29 & 27.70 & -4.85 \\
\hline \multicolumn{4}{|c|}{ B) Dipeptides } \\
\hline Trp-Ala & 0.165 & 15.75 & -2.75 \\
\hline Trp-Gly- & 0.162 & 15.60 & -2.73 \\
\hline Trp-Val & 0.120 & 11.60 & -2.05 \\
\hline Trp-Leu & 0.100 & 9.50 & -1.66 \\
\hline Trp-Tyr & 0.075 & 7.40 & -1.30 \\
\hline \multicolumn{4}{|c|}{ C) Tripeptides } \\
\hline Leu-Leu-Ala ${ }^{-}$ & 0.293 & 28.20 & -4.95 \\
\hline Leu-Leu-Gly & 0.290 & 28.00 & -4.91 \\
\hline Leu-Leu-Leu ${ }^{-}$ & 0.240 & 23.20 & -4.05 \\
\hline Leu-Leu-Tyr ${ }^{-}$ & 0.205 & 19.70 & -3.45 \\
\hline Leu-Leu-Phe ${ }^{-}$ & 0.180 & 17.50 & -3.05 \\
\hline Leu-Gly-Phe & 0.275 & 26.50 & -4.65 \\
\hline Trp-Gly-Gly- & 0.165 & 15.80 & -2.75 \\
\hline Trp-Gly-Tyr & 0.165 & 15.00 & -2.65 \\
\hline Gly-Phe-Ala & 0.285 & 27.50 & -4.80 \\
\hline Gly-Phe-Gly- & 0.265 & 25.60 & -4.50 \\
\hline Gly-Phe-Tyr ${ }^{-}$ & 0.210 & 20.20 & -3.55 \\
\hline
\end{tabular}


(Table 3) contd.....

\begin{tabular}{|c|c|c|c|}
\hline Compounds & $\Delta \phi_{\mathrm{A}^{-}}^{\Theta^{\mathrm{W} \rightarrow \mathrm{NB}}} / \mathbf{V}$ & $\Delta G_{\mathrm{A}^{-}}^{\Theta_{\mathrm{w}} \rightarrow \mathrm{NB}} / \mathbf{k J ~ \mathbf { M o l } ^ { - 1 }}$ & $\log P_{\mathrm{A}^{-}}^{\theta_{\mathrm{w} \rightarrow \mathrm{NB}}}$ \\
\hline Phe-Gly-Gly & 0.300 & 29.00 & -5.10 \\
\hline Gly-Gly-Val- & 0.275 & 26.40 & -4.60 \\
\hline Gly-Gly-Leu- & 0.280 & 26.80 & -4.70 \\
\hline Gly-Gly-Tyr & 0.300 & 29.00 & -5.10 \\
\hline Gly-Leu-Gly- & 0.280 & 27.00 & -4.75 \\
\hline Gly-Trp-Gly & 0.165 & 15.80 & -2.75 \\
\hline Gly-Tyr-Gly ${ }^{-}$ & 0.280 & 27.10 & -4.75 \\
\hline Gly-Leu-Tyr & 0.245 & 23.40 & -4.10 \\
\hline Gly-Leu-Phe ${ }^{-}$ & 0.270 & 26.20 & -4.60 \\
\hline Gly-Ala-Phe & 0.285 & 27.40 & -4.80 \\
\hline Tyr-Lys-Thr ${ }^{-}$ & 0.255 & 24.60 & -4.30 \\
\hline Lys-Tyr-Thr & 0.310 & 30.00 & -5.25 \\
\hline \multicolumn{4}{|c|}{ D) Polypeptides } \\
\hline Tyr-Ala-Gly-Phe-Met ${ }^{\circ}$ & 0.190 & 18.40 & -3.30 \\
\hline Tyr-Ala-Gly-Met-Phe & 0.260 & 24.90 & -4.40 \\
\hline
\end{tabular}

experiments. However, it must be stressed that this process is enthalpy driven, whereas biological partitioning is usually entropy ruled [2]. Therefore, the lipophilicity itself of the drug, the membrane activity and the interactions between the drug and membrane constituents can play decisive roles in the effective transport of a given drug across the biological membranes. So, in the last few years, a huge number of electrochemical drug-membrane interaction studies have been reported using lipid-modified liquid-liquid interfaces.

The membrane activities of four ionisable therapeutic important drugs (aminacrine, tacrine, velnacrine and proflavine) were obtained by cyclic voltammetry and electrochemical impedance spectroscopy at water and nitrophenyloctyl ether interface [18]. These drugs possess different abilities to pass through biological membranes since positive interactions were observed between velnacrine and proflavine ionic forms and the polar groups of the various phosphatidylcholine fattyacids, which has been used as modifiers of the liquid-liquid interface. The electrochemistry of the protonated forms of two structurally related decapeptides of pharmaceutical interest (LHRH-leutinising hormone releasing hormone, and nafarelin) at the distearoyl phosphatidylcholine monolayer-modified water-nitrophenyloctyl ether interface was studied [56]. Although nafarelin is more lipophilic than LHRH, their membrane activities have been found to be in divergence. Kontturi et al. [57] have reported the liposome-water partition coefficients of several $\beta$-blockers (carteolol, metoprolol, nadolol, propranolol, and timolol) resulting form the interactions between the protonated drugs and dipalmitoyl phosphatidylcholines (DPPC) studied by voltammetry at liquid-liquid interface in a micropipette set-up. DPPC has also been used in the membrane interaction electrochemical studies of several protonated polyammonium antifungal agents at a modified waternitrobenzene interface [58]. No significant changes in the voltammetric currents were detected, when compared to those at bar liquid-liquid interface, which leads to the conclusion 
Table 4. Standard Partition Coefficients (Taken from Reference [37]) of the Monoanionic Forms of Several Pharmaceuticals Drugs and Drugs Determined with Three-Phase Electrode Voltammetry at Water and Nitrobenzene (NB), Water and Nitrophenyloctylether (NPOE), Water and n-Octanol (n-Oct), and Water and 1,2-Dichlorethane (DCE) Interfaces (Decamethylferrocene was Used as a Redox Probe)

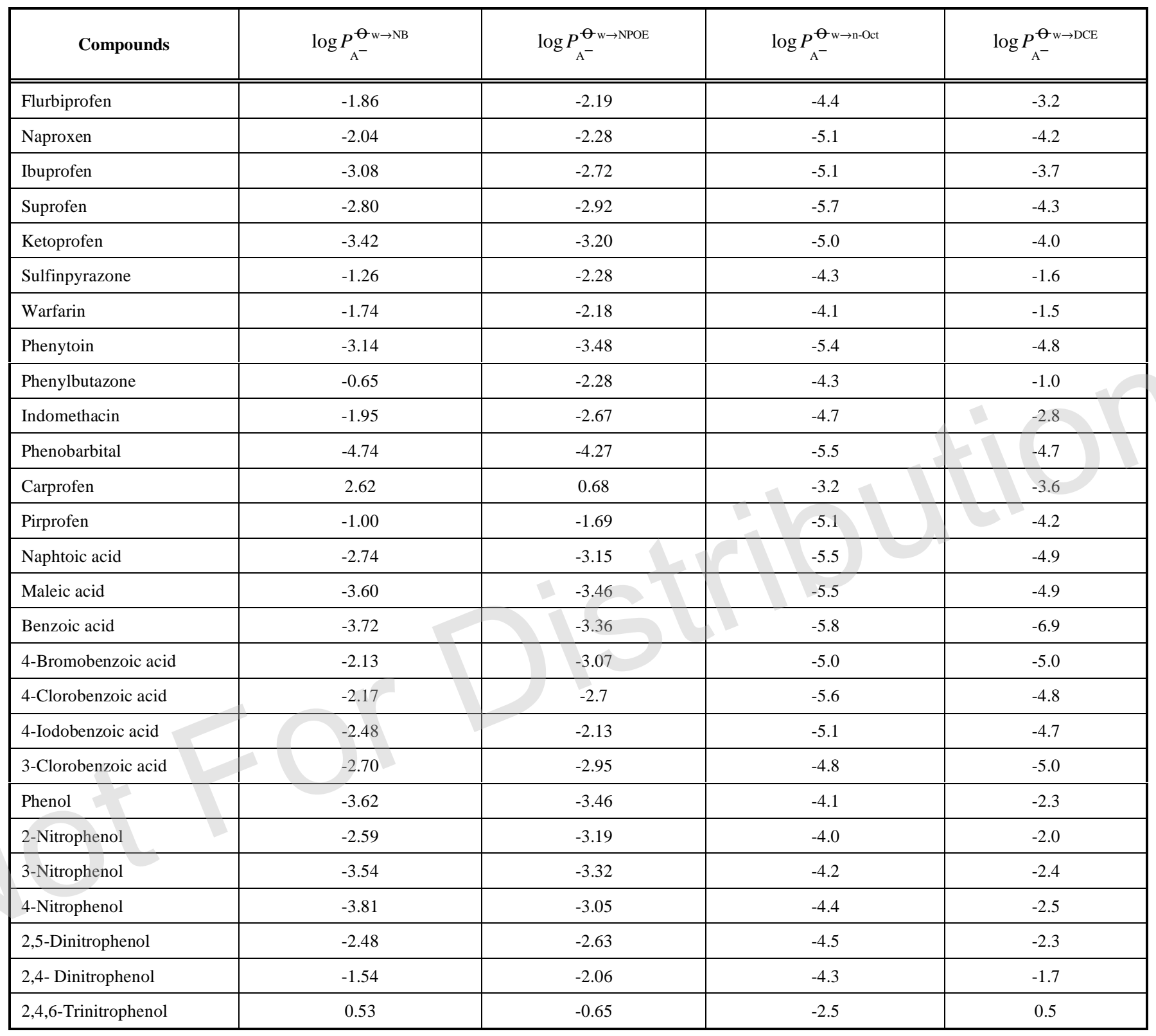

that the polyanion transfer process across biological membranes is not affected. In addition, a high permeability through the phospholipids layers at the water-nitrobenzene interface has been described [59]. The antibiotic gramicidin membrane activity in phospholipids layers has been reported $[60,61]$. Du et al. [62] performed a study on the ion transfer of the antiinflammatory drug ibuprofen across 1,2-dimyristoyl-snglycero-3-phosphatidylcholine modified liquid-liquid interface. It has been found that ibuprofen can, in low concentration, stabilize the membrane but induce defects formation.

Gulaboski et al. [63] have recently investigated the ion transfer and membrane activities of the neurotransmitter acetylcholine, concluding that the positively charged form can significantly interact with the polar parts of the dioleoyl- phosphatidylcholine that was used to modify the interface of water and dichloroethane The strength and the type of the interactions between the acetylcholine and dioleoylphosphatidylcholine have been determined by electrochemical impedance spectroscopy and square-wave voltammetry. The transfer of charged acetylcholine can be significantly rendered by the presence of some kind of phospholipid in the biomembranes. In addition, theoretical electrochemical models have been developed, which fully describe the behaviour of acetylcholine ion transfer across the biomembranes. Besides the phospholipids, other type of amine compounds like amines [64] and alkylanilines [65] have been successfully used as modifiers of the liquid-liquid interfaces. The ionisable drug-membrane interactions studies across the liquid- 
liquid interface mentioned above have been regarded as the most relevant published in recent years. Yet, to improve the reader's knowledge on this topic, the authors suggest reading the work of Volkov and Dryfe $[1,66]$.

\section{KINETICS OF ION DRUG TRANSFER ACROSS LIQUID-LIQUID INTERFACES}

An important function of a biological membrane is to provide a barrier to the outside world. However, for cell survival, nutrients and drugs must enter the cell and waste products have to leave. For this and many other reasons, it is crucial that membranes be selectively permeable. It is generally assumed that the lipophilicity of the substance is the main criterion for successful membranes permeation. Classically, the highly lipophilic neutral and non-polar drugs can cross the membrane almost without constraints [1,2]. However, some drawbacks have been described for ionized drugs: only the ionized drugs that contain high lipophilic structures will be able to cross the cell-membranes by passive diffusion. The drug transfer process across the membranes, as a rule, is not attained by simple diffusion, but is closely related to the type and strength of the drug-membrane interactions, mainly with phospholipids and proteins. Moreover, the potential difference on both sides of the membranes and the $\mathrm{pH}$, in particular, can affect significantly the rate of transfer across the membrane [1]. So, the evaluation of the ionisable drug transfer kinetics across the membranes is an important task, since it could reveal valuable data about the efficacy of a particular drug. The knowledge about the ion transfer kinetics, contrary to the thermodynamics is modest and much work is still need to be done in this field.

The physical parameter that describes the ion transfer drug rate across the membrane is the standard rate constant of ion transfer process across liquid-liquid interfaces, that is $k_{\text {it }}^{\ominus}$, a parameter that can be determined by using fourelectrode cyclic voltammetry and electrochemical impedance spectroscopy (EIS) at ITIES [1, 3]. However some problems concerning the reliability of kinetic determinations by these techniques still exist, which are mainly linked to the presence of significant ohmic drop and high charging currents [1]. In a recent study, it was shown that $k_{\text {it }}^{\theta}$ values of a series of ions determined by square-wave voltammetry are very similar to those determined by EIS [62]. It is worth noting that the recent values reported for the kinetics of ion transfer across liquid-liquid interfaces are one order of magnitude lower than the values for some ions reported previously [1, $3]$. By using the ac-impedance measurements at a liquidliquid interface, Mikhelson [67] obtained larger standard rate constants for ion transfers of some common cations. Also, Mirkin et al. [68] reported rapid ion transfer of several tetraalkylammonium cations in experiments preformed by steady-state voltammetry. The rapid rate of facilitated proton transfer with several alkylanilines at modified waterdichloroethane interfaces has also been described by Schiffrin et al. [65].

The transfer kinetic process of the ionic acetylcholine across a water-dichloroethane interface has been recently studied by cyclic voltammetry and EIS. A $k_{\text {it }}^{\ominus}$ value of $\sim 0.003 \mathrm{~cm} \mathrm{~s}^{-1}$ was found with both techniques [63]. The rates of ion transfer of several tetraalkylammonium cations and the anti-Alzheimer drug tacrine were studied in a rotating diffusion cell at the supported membrane [69]. The obtained $k_{\text {it }}^{\ominus}$ values ranged from 0.01 to $0.0001 \mathrm{~cm} \mathrm{~s}^{-1}$, which were much lower than the previously reported values $[1,3]$. Mirceski et al. [70] reported a significant achievement in the determination of the kinetics of ion transfer across liquidliquid interface.

The recent efforts to find more precise ion transfer kinetics determinations have led to the development of new processes based on microelectrodes [71] or microelectrochemistry at a microcapilary liquid-liquid interface [72]. The phenomenon of "quasireversible maximum" in square-wave voltammetric measurements at thin-film electrodes [73] has been described as a simple and valuable tool for determining the rate constants of ionisable compounds across the waternitrobenzene interface $[54,74]$. Yet, further studies on this topic are needed in order to gain insight into the phenomenon and processes that control the rate of ion transfer across membranes and biomimetic membranes.

\section{ORGANIC SOLVENTS USED IN BIOMIMETIC MEMBRANES}

Although classic solvents like nitrobenzene and 1,2 dichloroethane are still widely used as organic phases for ion transfer studies on mimetic membranes [1, 2, 5, 9, 75, 76], their relevance today is significantly decreased for two reasons: (i) toxicity, and (ii) the requirement of new solvents which can better mimic the biologic membranes. Actually, the development of the droplet electrochemistry technique has allowed the application of a broad spectrum of novel organic solvents, such as $n$-octanol [9, 36, 37, 77], nitrophenyloctyl ether $[9,37]$ and even chiral organic solvents like D- and L-menthol [38], or D- and L-2-octanols [39]. Although $n$-octanol has been viewed as a good mimetic solvent, its application in ion transfer studies has been limited due to its non-polarizability, a problem that has been overcome with the three-phase electrode approach. Shao and Pereira et al. [78] reported, for first time, the polarization of a nano-interface between water and $n$-octanol by using a modified version of the classical four electrode voltammetry at ITIES. Additionaly, nitrophenyloctyl ether (NPOE) emerged as a viable non-toxic organic solvent in experiments at the polarized liquid-liquid interface $[5,9,37,44,46,79-$ 82]. NPOE has a moderate dielectric constant and a high viscosity that makes it a good ionic solvent suitable for kinetic studies. Electrochemical ion transfer studies performed with nitrophenylphenylether [47] and other chlorinated organic solvents [83], like 1,6-dichlorohexane and 1,4dichlorobutane, can also be found in the literature. Recently, the ionic transfer across the liquid-liquid interface where ionic liquids are one of the phases has emerged as a very attractive field, mainly due to their extraordinary properties such as electrical self-conductance and catalytic features [8490].

\section{FUTURE TRENDS}

The requirements for a precise and rapid quantification of the partition coefficients of important ionisable drugs have 
been followed by a rapid development of various analytical electrochemical systems. In the future, it is anticipated that these types of electrochemical techniques could lead to the simultaneous analysis of a compound in a mixture or different compounds simultaneously by the use of multi-electrode potentiostats. Certainly, the success of applications using multichannel potentiostats will be intrinsically related to a increase in the knowledge of the ion transfer process at liquid-liquid interfaces. The development of a high-throughput method for $\log P$ measurements in microchips, based on several coupled techniques, and computer simulation methods (molecular dynamics simulations) will be definitely a future challenge [91].

In summary, the evaluation of partition coefficients and the complete elucidation of the mechanisms of the drug transfer process across living-cell membranes are found to be central instruments for drug design and essential to the understanding of the kinetics of its ADMET (Absorption, Distribution, Metabolism, Excretion and Toxicity), due to its relevance to a number of steps in the pathway between the administration of a drug and its biological endpoint.

\section{ACKNOWLEDGEMENTS}

R. Gulaboski thanks Fundação para a Ciência e a Tecnologia (FCT) of Portugal for a postdoctoral fellowship (SFRH/BPD/14894/2004). C. M. Pereira, F. Borges and J. Garrido acknowledge support from FCT (POCI/QUI/57679/ 2004) and POCI/SAU-FCF/58330/2004.

\section{ABBREVIATIONS}

ADMET = Absorption, distribution, metabolism, excretion and toxicity

$\mathrm{CV}=$ Cyclic voltammetry

DPPC = Dipalmitoyl phosphatidylcholine

EIS $\quad=$ Electrochemical impedance spectroscopy

IT $=$ Ion transfer

IT/ET = Ion and electron transfer

ITIES = Interface between two immiscible electrolyte solutions

6-MAM = 6-Monoacetylmorphine

MDA $=3,4-$ Methylenedioxyamphetamine

MDMA = 3,4-Methylenedioxymethamphetamine

NPOE $=$ Nitrophenyloctyl ether

PIGE = Graphite electrode

\section{REFERENCES}

[1] Volkov, A.G.; in Liquid-Liquid Interfaces in Chemical, Biological and Pharmaceutical Applications, M. Dekker New York, 2001, Vol. 95.

[2] Testa, B.; van de Waterbeemd, H.; Folkers, G.; Gay, R. in Pharmacokinetic Optimization in Drug Research, Wiley-VCH, Weinheim, Germany, 2001.

[3] Girault, H.H.; Schiffrin, D.J.; in Electroanalytical Chemistry, A Series of Advances, Electrochemistry of Liquid-Liquid Interfaces, (Ed.: A. J. Bard), M. Dekker, New York, 1989, Vol. 15, pp. 1-141.

[4] Leo, A.; Hansch, C.; Elkins, D. Chem. Rev., 1971, 71, 525.

[5] Alemu, H. Pure Appl. Chem., 2004, 76, 697.
[6] Marken, F. Phil. Trans. R. Soc. Lond. A, 2004, 362, 2611

[7] Scholz, F. Annu. Rep. Prog. Chem. Sec. C, 2006, 102, 43.

[8] Scholz, F.; Gulaboski, R. ChemPhysChem., 2005, 6, 16

[9] Osakai, T.; Katano, H. Bunseki Kagaku, 2005, 54, 251.

[10] Banks, C.E.; Davies, T.J.; Evans, R.G.; Hignett, G.; Wain, A.J.; Lawrence, N.S.; Wadhavan, J.D.; Marken, F.; Compton, R.G. Phys. Chem. Chem. Phys., 2003, 5, 4053.

[11] Samec, Z. Pure Appl. Chem., 2004, 76, 2147.

[12] Pereira, C.M.; Silva, F. Electroanal., 1994, 6, 1034

[13] Scholz, F.; Komorsky-Lovrić, Š.; Lovrić, M. Electrochem. Commun., 2000, 2, 112.

[14] Chen, Y.; Zhang, M. Q.; Li, F.; Sun, P.; Gao, Z.; Shao, Y.H. Sci. Chine Series B-Chem., 2004, 47, 24.

[15] Osakai, T.; Hirai, T.; Wakamiya, T.; Sawada, S. Phys. Chem Chem. Phys., 2006, 8, 985.

[16] Amemiya, S.; Yang, X.; Wazenegger, T.L. J. Am. Chem. Soc., 2003, 125, 11832.

[17] Yuan, Y.; Wang, L.; Amemiya, S. Anal. Chem., 2004, 76, 5570.

[18] Malkia, A.; Liljeroth, P.; K. Kontturi, Electrochem. Commun., 2003, 5, 473 .

[19] Zhan, D.P.; Mao, S.N.; Zhao, Q.; Chen, Z.; Hu, H.; Jing, P.; Zhang, M.Q.; Zhu, Z.W.; Shao, Y.H. Anal. Chem., 2004, 76, 4128.

[20] Beni, V.; Ghita, M.; Arrigan, D.W.M Biosens. Bioelectron, 2005, 20, 2097.

[21] Tsukatmoto, R.; Kusu, F. Bunseki Kagaku, 2003, 52, 865

[22] Zhang, M.; Sun, P.; Chen, Y.; Li, F.; Gao, Z.; Shao, Y. Chinese Sci. Bull., 2003, 48, 1234.

[23] Kubota, Y.; Katano, H.; Send, M. Anal. Sci., 2001, 17, 65

[24] Fernandez, R.A.; Dassie, S.A. J. Electroanal. Chem., 2005, 585 , 240.

[25] Fantini, S.; Clohessy, J.; Gorgy, K.; Fusalba, F.; Johans, C.; Kontturi, K.; Cunnane, J.V. Eur. J. Pharm. Sci., 2003, 18, 251

[26] Monzon. L.M.A.; Yudi, L.M. J. Electroanal. Chem., 2006, 591, 46.

[27] Gulaboski, R.; Cordeiro, M.N.D.S.; Milhazes, N.; Garrido, J.; Borges, F.; Jorge, M.; Pereira, C.M.; Bogeski, I.; Morales Helguera, A.; Naumoski, B.; Silva, A.F. Anal. Biochem., 2007, 361, 236.

[28] Guo, J.D.; Yuan, Y.; Amemiya, S. Anal. Chem., 2005, 77, 5711.

[29] Samec, Z.; Trojanek, A.; Langmaier, J.; Samcova, E. Electrochem. Commun., 2003, 5, 867.

[30] Ulmeanu, S.M.; Jensen, H.; Bouchard, G.; Carrupt, P.-A.; Girault, H.H. Pharm. Res., 2003, 20, 1317.

[31] Lam, H.H.; Pereira, C.M.; Roussel, C.M.; Carrupt, P.-A.; Girault, H. H. Anal. Chem., 2006, 78, 1503.

[32] Li, F.; Chen, Y.; Zhang, M.Q.; Jing, P.; Gao, Z.; Shao, Y.H. J. Electroanal. Chem., 2005, 579, 89.

[33] Mirceski, V.; Gulaboski, R.; Scholz, F. Electrochem. Commun., 2002, 4,813 .

[34] Gulaboski, R.; Mirceski, V.; Scholz, F. Amino Acids, 2003, 24 149.

[35] Gulaboski, R.; Scholz, F. J. Phys. Chem. B, 2003, 107, 5650

[36] Bouchard, G.; Galland, A.; Carrupt, P.-A.; Gulaboski, R.; Mirceski, V.; Scholz, F.; Girault, H.H. Phys. Chem. Chem. Phys., 2003, 5, 3748 .

[37] Gulaboski, R.; Galland, A.; Bouchard, G.; Caban, K.; Kretschmer, A.; Carrupt, P.-A.; Stojek, Z.; Girault, H.H.; Scholz, F. J. Phys. Chem. B, 2004, 108, 4565 .

[38] Scholz, F.; Gulaboski, R.; Mirceski, V.; Langer, P. Electrochem. Commun., 2002, 4, 659 .

[39] Scholz, F.; Gulaboski, R. Faraday Discuss., 2005, 129, 169.

[40] Wain, A.J.; Wadhawan, J.D.; Compton, R.G. ChemPhysChem., $\mathbf{2 0 0 3}, 4,974$

[41] Giovanelli, D.; Davies, T.J.; Jiang, L.; Jonesb, T.G.J.; Compton, R.G. Phys. Chem. Chem. Phys., 2004, 6, 3889.

[42] Davies, T.J.; Garner, A.C.; Davies, S.G.; Compton, R.G. ChemPhysChem., 2005, 6, 2633

[43] Davies, T.J.; Wilkins, S.J.; Compton, R.G. J. Electroanal. Chem., 2006, 586, 260.

[44] Niedziolka, J.; Murphy, M.A.; Marken, F.; Opallo, M. Electrochim. Acta, 2006, 51, 5897.

[45] Niedziolka, J.; Rozniecka, E.; Chen, J.Y.; Opallo, M. Electrochem. Commun., 2006, 8, 941 .

[46] Bonne, M.J.; Reynolds, C.; Yates, S.; Shul, G. ; Niedziolka, J.; Opallo, M.; Marken, F. New J. Chem., 2006, 30, 327.

[47] Schul, G.; Opallo, M.; Marken, F. Electrochim. Acta, 2005, 50, 2315 
[48] Stott, S.J.; McKenzie, K.J.; Mortimer, R.J.; Hayman, C.M.; Buckley, B.R.; Page, P.C.B.; Marken, F.; Shul, G.; Opallo, M. Anal. Chem., 2004, 76, 5364.

[49] Karyakin, A.A.; Vagin, M.Y.; Ozkan, S.Z.; Karpachova, G.P. J. Phys. Chem. B, 2004, 108, 11591.

[50] Vagin, M.Y.; Trashin, S.A.; Ozkan, S.Z.; Karpachova, G.P.; Karyakin, A.A. J. Electroanal. Chem., 2005, 584, 110.

[51] Vagin, M.Y.; Malyh, E.V.; Larinova, N.I.; Karyakin, A.A. Electrochem. Commun., 2003, 5, 329.

[52] Gulaboski, R.; Pereira, C.M.; Cordeiro, M.N.D.S.; Bogeski, I.; Silva, A.F. J. Solid State Electr., 2005, 9, 469.

[53] Quentel, F.; Mirceski, V.; L’Her, M. J. Phys. Chem. B, 2005, 109, 1262.

[54] Quentel, F.; Mirceski, V.; L'Her, M.; Mladenov, M.; Scholz, F.; Elleouet, C. J. Phys. Chem. B, 2005, 109, 13228.

[55] Malkia, A.; Lijeroth, P.; Kontturi, A.-K.; Kontturi, K. J. Phys. Chem. B, 2001, 105, 10884 .

[56] Malkia, A.; Lijeroth, P.; Kontturi, K. Chemm. Commun., 2003, 13, 1430.

[57] Ikonen, M.; Murtomaki, L.; Kontturi, K. J. Electroanal. Chem., 2007, 602, 189.

[58] Katano, H.; Murayama, Y.; Tatsumi, H.; Hibi, T.; Ikeda, T.; Kameoka, I.; Tsukatani, T. Anal. Sci., 2005, 21, 1529.

[59] Katano, H.; Muruyama, Y.; Tatsumi, H.; Hibi, T.; Ikeda, T.; Kameoka, I.; Tsukatani, T. Anal. Sci., 2005, 21, 1529.

[60] Nelson, A. Biophys. J., 2001, 80, 2694.

[61] Shirai, O.; Yamana, H.; Ohnuki, T.; Yoshida, Y.; Kihara, S. J. Electroanal. Chem., 2004, 570, 219.

[62] Du, L.W.; Liu, X.H.; Huang, W.M.; Wang, E.K. Electrochim. Acta, 2006, 51, 5754.

[63] Gulaboski, R.; Pereira, C.M.; Cordeiro, M.N.D.S.; Bogeski, I.; Ferreira, E.; Ribeiro, D.; Chirea, M.; Silva, A.F. J. Phys. Chem. B, $\mathbf{2 0 0 5}, 109,12549$.

[64] Fernandez, M.A.; Yudi, L.M.; Baruzzi, A.M. Electroanal., 2004, $16,491$.

[65] Melazquez-Manzanares, M. ; Schiffrin, D.J. Electrochim. Acta, 2004, 49, 4651.

[66] Dryfe, R.A.W. Phys. Chem. Chem. Phys., 2006, 8, 1869.

[67] Mikhelson, K.N. Chem. Anal., 2006, 51, 853.

[68] Cai, C.X.; Tong, Y.H.; Mirkin, M.V. J. Phys. Chem. B, 2004, 108, 17872 .
[69] Murtomaki, L.; Barker, M.H.; Monzanares, J.A.; Kontturi, K. J. Electroanal. Chem., 2003, 560, 95.

[70] Quentel, F.; Mirceski, V.; L'Her, M. Anal. Chem., 2005, 77, 1940.

[71] Tong, Ch. C.Y.; Mirkin, M.V. J. Phys. Chem. B, 2004, 108, 17872.

[72] Negishi, T.; Nakatani, K. Anal. Chem., 2005, 77, 1807.

[73] Mirceski, V. J. Phys. Chem. B, 2004, 108, 13719.

[74] Mirceski, V.; Quentel, F.; L’Her, M.; Pondaven, A. Electrochem. Commun., 2005, 7, 1122.

[75] Scholz, F.; Gulaboski, R.; Caban, K. Electrochem. Commun., $\mathbf{2 0 0 3}, 5,929$

[76] Komorsky-Lovric, S.; Riedel, K.; Gulaboski, R.; Mirceski, V.; Scholz, F. Langmuir, 2002, 18, 8000.

[77] Gulaboski, R.; Mirceski, V.; Scholz, F. Electrochem. Commun., 2002, 4, 277

[78] Jing, P.; Zhang, M.Q.; Hu, H.; Xu, X.D.; Liang, Z.W.; Li, B.; Shen, L.; Xie, S.B.; Pereira, C.M. ; Shao, Y.H. Angew. Chem. Int. Edit., 2006, $45,6861$.

[79] Shul, G.; Opallo, M. Electrochem. Commun., 2005, 7, 194.

[80] Jorge, M.; Gulaboski, R.; Pereira, C.M.; Cordeiro, M.N.D.S. Mol. Phys., 2006, 104, 3627.

[81] Jorge, M.; Gulaboski, R.; Pereira, C.M.; Cordeiro, M.N.D.S. J. Phys. Chem. B, 2006, 110, 12530.

[82] Liu, X.; Bouchard, G.; Girault, H.H.; Testa, B.; Carrupt, P.-A Anal. Chem., 2003, 75, 7036.

[83] Katano, H.; Tatsumi, H.; Senda, M. Talanta, 2004, 63, 185.

[84] Rozniecka, E.; Niedziolka, J.; Sirieix-Plenet, J.; Gaillon, L.; Murphy, M.A.; Marken, F.; Opallo, M. J. Electroanal. Chem., 2006, 587, 133.

[85] Hernandez, V.A.; Scholz, F. Electrochem. Commun., 2006, 8, 967.

[86] Nishi, N.; Murakami, H.; Imakura, S.; Kakiuchi, T. Anal. Chem., 2006, 78, 5805 .

[87] Tsujioka, N.; Imakura, S.; Nishi, N.; Kakiuchi, T. Anal. Sci., 2006, $22,667$.

[88] Tanaka, K.; Nishi N.; Kakiuchi, T. Talanta, 2004, 20, 1553.

[89] Schroeder, U.; Wadhawan, J.; Evans, R.G.; Compton, R.G.; Wood, B.; Walton, D.J.; France, R.R.; Marken, F.; Bulman Page, P.C.; Hayman, C.M. J. Phys. Chem. B, 2002, 106, 8697.

[90] Katano, H.; Tatsumi, H. Anal. Sci., 2003, 19, 651.

[91] Ulmeanu, S.M.; Josserand, J.; Jensen, H.; Bouchard, G.; Carrupt, P.-A.; Girault, H.H. J. Chromatogr. A, 2005, 1063, 89. 